\title{
Implementation of the Bologna system in higher education in Russia: problems and results
}

\author{
Larisa Nikolaevna Nabilkina ${ }^{11}$ Ekaterina Aleksandrovna Nikolaeva ${ }^{2}$ and Olga Nikolaevna \\ Chelyukanova $^{1}$ \\ ${ }^{1}$ Lobachevsky State University of Nizhny Novgorod (Arzamas branch), Department of Foreign \\ Languages and Cultures, Arzamas, Russia \\ ${ }^{2}$ Moscow City Pedagogical University, Institute of Pedagogy and Psychology of Education, \\ Department of Teaching Methods, Moscow, Russia
}

\begin{abstract}
The article is devoted to the analysis of the problems and prospects of Russia's innvolement in a single European area of higher education, better known as the Bologna process, its purpose being to create an unlimited scientific environment in the field of education and scientific activity. The study aims to consider the features of Russia's entry into the Bologna system, analyze the advantages and disadvantages of this process, and outline the importance of higher education in the formation of national identity and national mentality. The main research methods are system-analytical, comparative and axiological ones. Also, the study employs other methods relevant to the objectives of the work: the method of sociological observation, description, linguoculturological analysis. The problem of higher education integration is debated a lot in the pedagogical community. Our teachers, methodologists, culturologists also participate in scientific discussions. Despite a number of advantages, Russian education does not quite fit into the context of Western culture: the unification of the educational process leads to the destruction of scholarly traditions, the ideas of "educational tourism" and "double" diplomas cannot be fully implemented, especially in provincial universities, Russian universities fail to take their worthy place in international rankings. As a result, the authors of the article come to the reasonable conclusion that the task of the cultural and educational community is to preserve national identity, basic values, traditions of elite imperial education and their integration into European educational space. The main mission of university education is the formation of a universal educational idea based on the priority of the humanities. This is what scientists and educators should strive for, regardless of nationality and linguistic affiliation.
\end{abstract}

Keywords: culture, mentality, unification, personalization, national identity, competitiveness.

\section{Introduction}

\footnotetext{
${ }^{1}$ Corresponding author: nabilkina@yandex.ru
} 
Both secondary and higher education has always been the strong point of the Soviet system. It was orderly, based on traditional didactic and methodological principles, although being more fundamental than applied. However, this was not a disadvantage, since, having received solid and deep knowledge, the students could easily apply it and adapt to the situation at hand. The fact that Soviet physicists and geneticists were extremely in demand in laboratories around the world is no myth, it was a reality of the Soviet era. It is not without reason that, thanks to the remaining knowledge acquired during the Soviet times, Russian medicine managed to create the most successful version of the coronavirus vaccine and slow down the upsurge of the pandemic.

But during the period of reforms, when all aspects of our life were undergoing changes, education could not stand aside. The globalization process demands unification in everything, all spheres of activity are brought to a common denominator, the introduction of a single European currency being a vivid example. There appears an idea of creating a single European area of higher education, and to implement it, a Congress embracing 29 countries was set on June 19, 1999, in Italy. The purpose of this meeting was to create a limitless scientific environment in the field of education and scientific activity. Soon afterward, 48 more countries joined the system. Russia joined the Bologna Process in September 2003 [1].

The purpose of our study is to consider the features of Russia's entry into the Bologna system, to analyze the advantages and disadvantages of this process, to outline the importance of higher education in the formation of national identity and national mentality.

\section{Methods}

The main research methods are system-analytical, comparative and axiological ones. Also, the study employs other methods relevant to the objectives of the work: the method of sociological observation, description, linguoculturological analysis. These methods allowed us to come to reliable conclusions.

\section{$3 \quad$ Results and discussion}

The problem of higher education integration is actively discussed in the pedagogical community. Western colleagues are very positive on this matter. Thus, Whedon and Riddell in their article "Higher education in Europe" write about the need to "create a global higher education based on European ideals and economic interests" [2]. Meanwhile, they note that, according to the European Association of Universities, the autonomy of national systems should be preserved. Razayev in the pages of the International Encyclopedia of Education claims that the Bologna system "promotes the development of high-quality, competitive education and favors the development of student mobility in the world labor market". "By way of self-sacrifice, we must achieve a common goal," sums up the scientist [3]. Similar views are expressed by the Norwegian scholar Karlsen who says that the Bologna Process will allow the European Union to become "the most dynamic educational economy in the world", noting that "a teacher is the most mobile profession in the world" [4].

The Bologna system is focused on acquiring a certain set of competencies that allow working effectively in modern conditions. It is the competencies, and not the marks in the diploma, that guarantee a high quality of work and, as a result, advancement on the career ladder. The term "competence" has different interpretations, and its understanding largely depends on the national specifics. The generally accepted definition is as follows: the 
ability to achieve certain results in the work, individual abilities, personal qualities and professional skills necessary to perform any kind of work [5]. Integration and cost-effectiveness are the main characteristics of the Bologna System. This means that a universal educational system is being created, learning fits into a shorter time frame and, therefore, financial costs are reduced [6].

The most conspicuous change that our education has undergone having entered the Bologna process, is the transition to a three-level system, in which a doctoral degree is a component of higher education, not postgraduate education, as it was before. Basic and variable parts appear in the curriculum, i.e. a significant number of hours are now devoted to elective disciplines. At the same time, programs are being unified and tend to uniformity so that educational tourism and student mobility become available [7]. Thanks to this, a student can enter, for example, a provincial university, study for a year, continue their studies in Moscow, and then in Prague or Warsaw. Unified programs within a certain profile are really allow to do so. The difficulty lies only in the fact that students should be fluent in English, and, moreover, it should not be "general English", but the so-called "English for specific purposes", so that they would be able to understand a lecture on mathematical analysis or talk in seminars about the problems of genetic engineering.

The undoubted advantage of the Bologna system is the system of "double" diplomas [8]. Thus, having received education in one country, a graduate can work in the relevant sphere abroad. In this case, confirmation of qualifications is not required. Undoubtedly, this is a very convenient and progressive innovation, thanks to which the exchange of knowledge, technology and human resources takes place. This makes it possible for them to absorb the foreign experience and generously share their own. This becomes a reality, thanks to a unified teaching system. The training is built on the principle of obtaining "credits", which is based on the European Credit Transfer System. By the end of the course, the student should have achieved a certain number of such points [9].

Almost twenty years have passed since Russia entered the Bologna process, and some results can be summed up. As shown by numerous surveys, the training level of graduates has significantly decreased. The bachelor's degree training does not develop a broad outlook, but is aimed at the formation of several competencies, and the number of hours allocated for mastering disciplines has been reduced compared to the specialist's degree program by almost half [10]. The time spent at the university has also been reduced from 5 to 4 years, as is standard in Western countries. But you should remember that young Germans and Italians study at school for twelve years, that is, one year longer than Russians. Teachers notice that they are critically lacking time needed to fully explain the material. Supporters of the Bologna system explain that in the classroom, the lecturer only sets the direction, draws the vector, and the students must study the material on their own. But, as practice shows, future bachelors are not ready to "acquire knowledge" neither intellectually nor psychologically [11]. A Master's degree could partly fill this gap, but not all students continue their studies, believing that a bachelor's degree is quite enough, and you need master's (as it was actually intended) to conduct scientific research. In addition, another problem arises for professors teaching in the master's level. According to the current standards, a bachelor graduate can change the direction of their educational trajectory and, being a lawyer, enroll in a master's degree in linguistics, or being an economist, enroll in psychology. So teachers cannot give in-depth knowledge in a certain area, but have to actually start all over again. Another problem concerns electives and the related problem of credits. It would seem that training becomes personalized, students consciously chooses what will be useful for them in their future professional activity and study the material more thoughtfully. However, in practice, it turns out that students follow 
the path of "least resistance" and choose unnecessary, but easy subjects only in order to gain the required number of credits [12]. This problem is not new. The United States already faced it in the 1960s in secondary school education, when high school students chose home economics instead of physics, and driving lessons instead of algebra. And only the introduction of the proficiency test made it possible to improve the situation.

The basic principle of Russian education has always been its fundamental and systematic nature. The deductive method underlying this principle, i.e. leading from the broadest possible generalizations to local manifestations and to practice. The Anglo-Saxon model, on the other hand, leads from concrete examples to unified knowledge [13].

A significant problem also arises concerning the unification of the educational process, which is trying to integrate Russia into the Western system. First of all, this leads to destruction of scholarly traditions that existed in all large universities, where teachers and students conducted their scientific research under the guidance of venerable professors. This made it possible to achieve results in a certain scientific field and served as the basis for the uniqueness of a certain university. Perhaps this can be a fertile ground for educational and scientific "tourism", which makes an integral part of the Bologna process. But if all universities teach according to the same template, if there is no scientific discussion thanks to which new ideas are generated, why then scientific tourism is needed? In the 1950s, Erich Auerbach in his work "Philology of World Literature" wrote that world literature is poised to disappear, since dialogue is possible only between different entities, and if everything is the same in all countries, then there is no sense in discussion and development [14]. This can be fully attributed to the education system.

The idea that the diplomas of Russian universities would be fully recognized abroad also turned out to be nothing more than a myth. There are very few universities that issue "double" diplomas. Most of such documents require confirmation. It should be noted that elite British and American universities, such as Oxford or Harvard, do not operate according to the Bologna system, and their graduates of any specialty are valued all over the world [15].

Supporters of the Bologna system argue that educational integration will allow Russian universities to enter international rankings, thereby indicating their high status. In the QS World University Ranking 2020/21 presenting 1000 best universities in the world, you can find 28 Russian universities. "Top" universities look rather modest against this background: Moscow State University rates 74th, St. Petersburg State University 225th, and the National Research University Higher School of Economics, which is the leader in promoting the Bologna system in our country and the flagship of online education, 298th.

\section{Conclusion}

Thus, we see that Russian education does not quite fit into the context of Western culture, and this is not because one system is bad and the other is good. Even Nickolay Berdyaev wrote that individualism is characteristic of Western culture, and collegiality for Russian culture [16]. The task of the cultural and educational community is to preserve national identity, basic values, traditions of elite imperial education and their integration into the European educational space. The main mission of university education is the formation of a universal educational idea based on the priority of the humanities. This is what scientists and educators should strive for, regardless of nationality and linguistic affiliation. 


\section{References}

1. D. Rich, The Bologna Process in European Higher Education, in E. Baker, B. McGaw (eds.), International Encyclopedia of Education, Penelope Peterson, 215-219 (Elsevier, 2010)

2. E. Weedson, Sh. Riddell, Higher education in Europe: Widening participation, in M. Shah, A. Bennett, E. Southgate (eds.), Widening Higher Education Participation: A Global Perspective, 49-62 (Chandos Publishing, 2016)

3. A.V. Razaev, Bologna Process, in E. Baker, B. McGaw (eds.), International Encyclopedia of Education, Penelope Peterson, 306-312 (Elsevier, 2010)

4. G. Karlsen, The role of governance of teacher education, in E. Baker, B. McGaw (eds.), International Encyclopedia of Education, Penelope Peterson, $532-539$ (Elsevier, 2010)

5. M. Lokse, et al., Learning strategies, in Teaching Information Literacy in Higher Education, 51-68 (Chandos Publishing, 2017) https://doi.org/10.1016/B978-0-08-100921-5.00004-7

6. M. Shah, Ch.S. Nair, J.T.E. Richardson, Student Engagement in National Quality Assurance, in Measuring and Enhancing the Student Experience, 123-131 (Chandos Publishing, 2017). https://doi.org/10.1016/B978-0-08-100920-8.00011-3

7. K. Vangrieken, et al., Teaching and Teacher Edu. 61, 47-59 (2017). https://doi.org/10.1016/j.tate.2016.10.001

8. Zh. Hong, Sh. Lou, Development and reform of higher education in China (Chandos Publishing, 2011)

9. C. Maybee, IMPACT Learning (Chandos Publishing, 2018)

10. I.V. Fomichev, Law and Edu. 5, 53-67 (2011)

11. A.A. Polyakova, Col. Works SWORLD, 4, 31-35 (2013)

12. A.S. Olnev, N.M. Rumyantsev, Bolonskii protsess v Rossii i povyshenie mobilnosti obrazovatelnykh protsessov [The Bologna Process in Russia and Increasing Mobility of Educational Processes], in Current Issues of Modern Science (Moscow, 2011)

13. Yu.V. Zadorozhny, Higher Edu. Today, 4, 49-52 (2016)

14. E. Auerbach, Filologiya mirovoi literatury [Philology of world literature] (Cultural Revolution, Moscow, 2021)

15. M. Vaskevich [The Bologna Process in higher education in Europe] (Luxembourg, 2017)

16. N. Berdyaev, Russkaya ideya [Russian Idea] (ABC Classics, St. Petersburg, 2008) 